\title{
A antropofagia encontra O MARXismO notas a propósito de 0 rei da vela, de Oswald de Andrade
}

\author{
Eduardo de Assis Duarte \\ UFMG
}

\begin{abstract}
Cuándo fue nunca tan útil decir la verdad?
Cuándo fue la verdad tan necessaria e intervino tan directamente? Bertolt Brecht
\end{abstract}

\section{RESUMO}

Este texto procura relacionar a modernidade de $\mathrm{O}$ rei $\mathrm{da}$ vela com o proje to político de seu autor, Oswald de Andrade, bem como apontar certas confluências com a prática teatral de Brecht, Piscator e Meyerhold.

\section{PALAVRAS - CHAVE}

antropofagia, vanguarda, engajamento, marxismo

Oswald de Andrade tornou-se célebre pela radicalidade de suas postulações estéticas ao longo dos anos 20. No entanto, seu teatro só irá surgir mais tarde, no calor dos embates sociais e políticos que sacodem o Brasil na década seguinte. Suas peças $O$ rei da vela, $O$ homem e o cavalo e $A$ morta, escritas após a adesão ao Comunismo, põem em prática um teatro de intervenção social, sendo vítimas de um sintomático "esquecimento", tanto por parte da crítica, afinada com o paradigma moderno, quanto do próprio meio teatral. Por muito tempo, somente $\mathrm{O}$ rei da vela conseguiu ser levado ao palco por uma grande companhia profissional, na histórica montagem feita por José Celso Martinez Correia, em 1967, trinta e quatro anos após ter sido escrita.

Há na crítica brasileira uma tendência a dividir a obra de Oswald de Andrade em duas fases: a dos anos 20 e a dos anos 30, isto é, antes e depois do marxismo. Em parte, isto se deve ao próprio Oswald, que renegou bombasticamente parte de sua produção anterior no conhecido prefácio a Serafim Ponte Grande, publicado em 1933. Ao longo do tempo, a crítica e a historiografia se encarregaram de ir lentamente deslocando do centro da obra oswaldiana não só o teatro, mas igualmente os dois volumes de Marco Zero. Os escritos vindos a público entre 1930 e 1945 , por evidenciarem as marcas da guinada à esquerda, foram sendo empurrados para uma espécie de vala comum dos textos rotulados como "menores" ou formalmente conservadores em função de estarem a serviço de um determinado projeto político, como se os escritos dos anos 20 também não possuíssem sua faceta política. Nos dias de hoje, pensamos ser possível uma outra leitura, menos dicotômica e mais infensa, talvez, ao reducionismo. Opor vanguarda a engajamento implica não levar em conta a demolição dos valores patriarcais e burgueses presente nos escritos dos anos 20 , que antecipam a 
ruptura mais radical operada na década seguinte. Implica, por outro lado, desconsiderar, por exemplo, todo o aparato formal que sustenta $O$ rei da vela, texto construído a partir de inovações simplesmente revolucionárias para o teatro brasileiro daquela época.

Já o Manifesto da Poesia Pau-Brasil - exacerbação das propostas da Semana de Arte Moderna de 1922 - inscrevia o pendor oswaldiano para as culturas reprimidas no processo histórico brasileiro, para a captação das heranças indígena e negra e para o encontro sem preconceitos com as práticas culturais das classes populares. A sedução exercida pela cultura do Outro leva-o a celebrar os "casebres de açafrão e de ocre nos verdes da favela" como "fatos estéticos" e a clamar pela "contribuição milionária de todos os erros", que, aliada à "originalidade nativa", serviria de contrapeso às "indigestões de sabedoria" e à "adesão acadêmica" da cultura brasileira. ${ }^{1}$

Essa busca do outro acentua-se no Manifesto antropófago, de 1928, onde não apenas sugere, mas põe efetivamente em prática a "devoração crítica", isto é, a superação, se pensarmos em termos propriamente marxistas, da cultura dominante - branca, masculina, ocidental e cristã. Pautado numa compreensão absolutamente contemporânea da diferença cultural, que traz em seu bojo corolários como o da tolerância - étnica, estética, entre outras - a antropofagia propõe o desrecalque da fala do Outro e reverencia a herança primitivista, com seus acentos matriarcais: "já tínhamos [antes da chegada dos brancos] o comunismo (...) tínhamos a relação e a distribuição dos bens físicos, dos bens morais, dos bens dignários", " afirma Oswald, leitor que vinha de Freud e Nietszche e encontra Marx e Engels. O Manifesto antropófago dialoga com A origem da família, da propriedade privada e do estado ao reproduzir as concepções de Engels a propósito do comunismo primitivo e de seu desaparecimento devido à emergência da propriedade privada e da necessidade de transferir os bens de pai para filho através de herança.

Entre a revolução antropológica e filosófica expressa nas teses de 1928/29 e a militância mais explicitamente política dos anos 30, o pensamento oswaldiano penetra numa perspectiva de radicalização, centrada na dominância do fator econômico. Nesse breve intervalo de tempo, dá-se a crise mundial decorrente do crack da Bolsa de New York e o abalo financeiro do escritor que, sendo até entāo um rico herdeiro de fazendas de café, se tornará o primeiro aristocrata brasileiro a aderir ao comunismo. Em 1931, ele edita, juntamente com a escritora Patrícia Galvão, o jornal panfletário O Homem do powo, que sobreviveu a poucos números em função da crítica áspera ao sistema econômico e político vigente no Brasil. Dois anos mais tarde, vem à luz o romance experimental Serafim Ponte Grande, em cujo prefácio renega a vida e a literatura burguesa e declara seu propósito de ser "o casaca de ferro da revolução proletária". ${ }^{3}$ É este contexto, pois, que preside à construção da peça que passamos a examinar.

O texto de O rei da vela trata da ascensão e da queda de Abelardo I, um arrivista enriquecido às custas da crise econômica de 1929. O personagem constrói sua fortuna emprestando dinheiro a juros elevados e depois liquidando as dívidas e apossando-se dos bens de seus clientes. Além disso, usufrui dos lucros de uma fábrica de

\footnotetext{
${ }^{1}$ Andrade. Manifesto da Poesia Pau-brasil, p.5-10.

${ }^{2}$ Andrade. Manifesto Antropófago, p.13-19.

${ }^{3}$ Andrade. Serafim Ponte Grande, p. 9.11 (prefácio).
} 


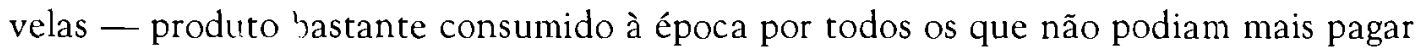
a conta de ericrgia elétrica. Entre as principais vítimas do agiota estão os representantes da burguesia rural subitamente empobrecida com a queda dos preços agrícolas no mercado internacional. É dessa elite agrária falida que surge Heloísa de Lesbos, noiva de Abelardo I. A relação entre os dois é representada como uma simples transação mercantil, ele entrando com o dinheiro e ela com o nome de família. Ao final, Abelardo I é traído e levado à ruína por um de seus funcionários, denominado sintomaticamente Abelardo II. Além de ficar com o dinheiro do patrão, Abelardo Il termina tomando-lhe também a noiva. A peça se encerra ao som da marcha nupcial e do grito de "Oh! Good business!" proferido por $\mathrm{Mr}$. Jones, o magnata americano a quem todos bajulam.

É preciso destacar, inicialmente, o sentido paródico/antropofágico que preside à construção deste Rei da vela, não só como personagem, mas também enquanto formulação discursiva. A metáfora da vela - objeto cuja existência carrega o sentido da efemeridade material e de uma luz fraca e de pouca duração - indica a fragilidade da fortuna acumulada através da agiotagem em tempos de crise. De um só golpe, o poder de Abclardo I "se desmancha no ar" antes mesmo que ele possa consolidar sua posição social pela via do casamento. Já sua união com Heloísa de Lesbos visa devorar/parodiar o mito do amor eterno oriundo do discurso burguês e tornado célebre a partir de sua concretização nas venturas e desventuras do homônimo casal. O Abelardo moderno é o antípoda de seu longínquo ancestral e a Heloísa de agora é, simplesmente, de Lesbos... Ambos funcionam como duplos destronantes dos personagens inscritos no mito, evidenciando o anacronismo deste em tempos de hegemonia do capital. O que se pode vislumbrar apenas por estes dois exemplos não é um fosso separando a ruptura estética do texto engajado. Ao contrário, vê-se o encontro da antropofagia com o marxismo. A devoração estética dos mitos - como o da paixão romântica ou o do self made man encarnado/desmascarado pelo protagonista - está embasada num pensamento que busca a superaçāo moral e política do sistema ideológico que sustenta tais formulações.

Já numa primeira leitura, pode-se perceber a interação entre vanguarda e engajamento. A peça busca conjugar dialeticamente crítica social e linguagem de invenção, ostentando uma modernidade inexistente no teatro brasileiro da década de 30, imerso ainda nas malhas do ilusionismo naturalista. Oswald toma o partido dos excluídos, mas recusa-se a idealizá-los nos moldes do realismo socialista. O tom é desmascaramento, a começar pelo desmascaramento do próprio gesto teatral, enfatizado a todo instante em seu sentido de representação. Desfaz-se a quarta parede, palco e platéia, atores e público fazem parte de um só e mesmo mundo, o mundo regido pelo capital.

O texto oswaldiano insere seu jogo cênico no âmbito do processo de distanciamento, precisamente com o intuito de questionar e subverter a ilusão naturalista. As figuras humanas são concebidas de forma a impedir a empatia e a identificação com os receptores. A ruptura com a catarse aristotélica se explicita ao longo de toda a peça, com alusões contínuas ao "ponto", ao "maquinista" e às “... soluções fora da vida..., soluções no teatro. Para tapear..." Assim, a postura que denuncia o capitalismo enquanto sistema

\footnotetext{
${ }_{4}^{4}$ ANDRADE. O rei da vela, p.103.
} 
de exploração econômica é a mesma que, em sua contrapartida estética, denuncia o teatro burguês como aparelho ideológico veiculador da alienação e do conformismo.

$\mathrm{Na}$ década seguinte, Bertolt Brecht assim teorizaria a atitude distanciadora:

Para produzir o efeito de distanciamento, o ator deve por de lado tudo o que havia aprendido antes para provocar no público um estado de empatia perante as suas configurações. Além de não tentar induzir o público a qualquer espécie de transe, o ator não deve também colocar-se em transe. (...) Em momento algum deve o ator transformar-se completamente na sua personagem. (...) Os sentimentos pessoais do ator não devem ser, em princípio, os mesmos que os da personagem respectiva, para que os do público não se tornem também, em princípio, os da personagem. ${ }^{5}$

Escrito em 1948, o "Pequeno organon para o teatro" revela um Brecht empenhado em construir uma dramaturgia que acarrete a reflexão e a crítica, superando assim a idéia do espetáculo movido a emoção e voltado para o alívio das tensōes do espectador. Apesar de, no Brasil, os ensinamentos de Brecht terem se transformado em paradigma do teatro engajado e, mesmo, quase em palavra de ordem, somente a partir dos anos 60, é precisamente esta a postura dos personagens oswaldianos dos anos 30. Eles são alegóricos, excessivos, caricaturais. Figuras concebidas de forma a remeter o público de volta aos problemas que o atormentam no cotidiano. Logo no início de $O$ rei da vela, após a primeira cena com uma das vítimas no escritório de agiotagem, Abelardo I recusa-se a atender novos clientes, mesmo estando cheia a jaula em que é representada a sua sala de espera: “...esta cena basta para nos identificar perante o público", 6 afirma o capitalista. O clima de estranhamento provocado pelo cenário completa-se com a afirmativa do personagem. Desfaz-se o encantamento da cena meramente recreativa e o público passa também a ser assunto discutido no palco. Em seu preciso estudo sobre Oswald de Andrade, Lúcia Helena ressalta que esta era uma prática só encontrada em pouquíssimos trabalhos da dramaturgia européia de vanguarda, como os de Meyerhold e Piscator, fato que demonstra o quanto Oswald era contemporâneo dos compagnons de route europeus que passavam a compreender a arte como gesto político. ${ }^{7}$

O distanciamento é ainda enfatizado por outros elementos de composição como a metalinguagem crítica do teatro burguês, a cenografia e o figurino construídos de forma a provocar o estranhamento, a fragmentação expressa nos cortes bruscos e no contraponto polifônico de vozes, além do humor corrosivo inscrito em forma de ironia, de sátira mordaz, de caricatura e paródia, tudo isso confluindo para a representação carnavalizadora das classes dominantes brasileiras e de suas instituições.

No primeiro caso, trata-se de veicular a crítica aos esquemas passadistas do nosso teatro de então, que oscilava entre os dramalhões românticos e peças de extração naturalista. Abelardo I ironiza o "arsenal moralista do teatro de nossos avós." E acrescenta: "Nada disso me impressiona nem impressiona mais o público..." Podemos notar que o tom é o mesmo do Manifesto Antropófago quando este afirma: "Estamos fatigados de todos os maridos católicos suspeitosos postos em drama" ou ainda do Manifesto

\footnotetext{
${ }^{5}$ BRECHT. Estudos sobre teatro, p. 118.

${ }^{6}$ Andrade. O rei da vela, p.17.

${ }^{7}$ Helena. Tótens e tabus da modemidade brasileira, p. 108.
} 
da poesia do pau-brasil, quando critica o teatro de tese e a "luta entre morais e imorais". Assim, ao mesmo tempo em que reitera a esclerose da moral burguesa, ultrapassada pelos novos tempos e pela violência da exploração capitalista, o texto ridiculariza a dramaturgia centrada nesses valores, além de provocar no público a necessária reflexão a respeito de um teatro que, em termos formais, não havia ainda adentrado no século XX.

Quanto a cenários e figurinos, sua funçāo é da maior importância para a edificação do clima irreverente da peça. O cenário do escritório de usura do primeiro ato não deixa dúvidas quanto à intenção de chocar e, mesmo, provocar a aversão do espectador. Composto por um retrato da Gioconda, caixas empilhadas, um divã futurista, uma secretaria Luís XV, um castiçal de latão e um telefone, o cenário expõe um amontoado desordenado e kitsch de estilos embaralhados. Essa mistura acarreta o estranhamento, ao mesmo tempo em que deixa claro o papel da arte na sociedade capitalista, qual seja o de mercadoria despida de qualquer aura. O estranhamento se completa com a visão do mostruário de velas de todos os tamanhos, das grades da jaula onde se amontoam os clientes e do prontuário onde estão fichados. O cenário da casa de agiotagem explicita ao extremo o caráter de exploração e de dominação inerente à estrutura que faz circular os bens e as mercadorias. A jaula cheia de desvalidos, mais o chicote de Abelardo II não deixam dúvidas quanto à representação do capitalismo como uma prisão e dos donos do dinheiro como guardiães desse cárcere. A aparente falta de harmonia entre as peças do cenário como que as isola, ampliando assim a carga de sentido de cada uma delas e transformando o escritório numa alegoria do próprio processo de acumulação capitalista.

Essa mesma iconicidade instigante encontra-se no cenário da ilha carioca do segundo ato, no qual vê-se a formação de um ambiente desigual, contrastando idílicas árvores e pássaros tropicais com um rádio, uma lancha e um avião, tudo isto coroado pela presença da bandeira americana, pairando sobre as cabeças... Na verdade, esse é o cenário ideal para as investidas de Mr. Jones, o representante do grande capital internacional, por sobre Heloísa e demais "morenas seminuas". ${ }^{8} \mathrm{O}$ segundo ato figura assim como uma grande paródia do nosso processo de colonização, a história se repetindo como farsa. Só que agora interessa ao colonizador branco, não o sexo primitivo de uma Iracema - personagem romântica que simboliza na literatura brasileira o sacrifício da mulher indígena no processo de colonização miscigenadora mas a "franca camaradagem sexual" com a burguesia brasileira repentinamente falida diante da crise econômica internacional.

Já o ambiente do terceiro ato difere dos anteriores pela homogeneidade que apresenta. Agora, é a vez de se amontoarem os restos mortais de uma casa de saúde penhorada pelo agiota: ferro-velho, maca, cadeira de rodas. É o cenário anunciando o próprio fim de Abelardo I e de seu reinado bufo. É a falência materializada nos ícones presentes na cena escura, sem luz elétrica e até sem o prontuário.

Desta forma, evidencia-se a integração semiótica inovadora praticada na peça. Nela se interseccionam dialeticamente verbal e icônico, palavra e imagem, som e luz,

\footnotetext{
${ }^{3}$ ANDRADE. O reida vela, p.55.

${ }^{9}$ IBIDEM.
} 
gesto e entonação. Muitas vezes é o texto que emoldura o ambiente e não o oposto. Nesses momentos, cenários, figurinos, gestos e açóes falam por si e encontram quase sempre na linguagem verbal apenas uma instância reiteradora, como no caso do cliente que usa como gravata uma corda amarrada no pescoço. De outras vezes o icônico se contrapĩe ao verbal a fim de the dar uma conformação irônica ou sarcástica. É o caso, por exemplo, de Abelardo II, vestido em traje de domador de feras, revólver na cintura, afirmar, depois de expulsar os clientes em desespero, ser "o primeiro socialista do teatro brasileiro". ${ }^{10}$

Mas a integração de códigos não se limita aos dois personagens citados. Heloísa de Lesbos surge pela primeira vez en cena vestida de homem, a fim de reiterar a condição já expressa pelo nome. A faca ostentada pelo intelectual Pinote é de madeira, tāo inofensiva quanto ele, homem de letras a serviço dos poderosos. Da mesma forma, Abelardo II aparece no terceiro ato não como domador, mas exageradamente caracterizado como ladrão. Tudo isso nos encaminha para o procedimento adotado na construção de figurinos e personagens, qual seja, o de apresentar estes últimos sempre como estereótipos inteiriços e unidimensionais. Isto se deve à necessidade de chamar atenção não para as figuras humanas e seu mundo interior, mas para a relações vividas e suas determinações sociais.

O humor se constitui no grande eixo de sustentação do texto oswaldiano. Nele, o palco se transforma num "mundo circense, selvagem e agitado, repleto de aventureiros, prostitutas, charlatães, palhaços", conforme nos ensina Anatol Rosenfeld. "Consciente da força crítica do riso, Oswald de Andrade lança mão de todos os procedimentos disponíveis para alcançá-lo. O que se tem como resultado é a desconstrução irreverente tanto da aristocracia rural $\mathrm{cm}$ decadência, quanto da burguesia em ascensão. No primeiro caso, temos a família do coronel Belarmino bastante caricatural, com personagens exageradamente marcados por desvios sexuais e levados à cena com intençōes eminentemente satíricas. Em certos momentos, avulta o grotesco das propostas sexuais de Abelardo I a D. Poloca, velha fidalga guardiã da moral patriarcal, mas que chega a admitir com certo prazer as investidas do usurário. E não é à toa que seu nome lembra "polaca"...

Nenhum dos personagens escapa à corrosão bem humorada presente no texto. Abelardo I age como rei bufão, sẹja curvando-se até os pés quando da entrada de Mr. Jones, seja na fala marcada pela total falta de sutileza ou meios-termos. Daí advém que os valores expressos em seu discurso sejam desmascarados de todo o véu de atenuações e hipocrisias. Até sua morte é carnavalizada, pois, na hora do suicídio, o que se ouve são os tiros de canhão e não de revólver.

Por outro lado, a substituição de Abelardo I por Abelardo II na direção dos negócios e na posse de Heloísa explicita de modo didático o substrato materialista dialético que estrutura as ações e procedimentos adotados. A peça enfatiza a ação dos mecanismos de poder, sobretudo os do poder cconômico, de forma a também corroer os mitos que recobrem seu significado social. O rei da vela deixa claro que o poder, no capitalismo, muda de mãos, mas nunca de donos:

\footnotetext{
${ }^{10}$ AndRade. O rei da vela, p. 30.

$"$ Cf. Teatro modemo.
} 
ABELARDO I

Um homem não tem importância... A classse fica. Resiste. (...)

ABELARDO II

Nu. $\mathrm{r}$ que chame um médico?

ABELARDO I

Para quê? Para constatar que eu revivo em você? E portanto que Abelardo rico não pagará a conta do Abelardo suicida? (...) Diga, onde escondeu o dinheiro que abafou?... ABELARDO II

Que dinheiro?

ABELARDO I

O nosso. O que sacou às dez horas precisas da manhã. $O$ dinheiro de Abelardo. $O$ que troca de dono individual mas não sai da classe. O que, através da herança e do roubo, se conserva nas māos fechadas dos ricos. ${ }^{12}$

É este o tom do final da peça. A retórica marxista vai aos poucos se mesclando às construções de perfil humorístico e marcando o texto com o discurso da crítica e da pedagogia esquerdista. Moribundo, o arrivista falido ordena que se sintonize a Rádio de Moscou. Ouvem-se os acordes da Internacional, o "hino dos trabalhadores", que "sairão um dia das catacumbas das fábricas". ${ }^{13}$ Antes de morrer, Abelardo I refere-se a si próprio como traidor de sua origem social: "traí a minha fome". ${ }^{14}$ Quanto a Heloísa, enxuga as lágrimas de crocodilo e ampara-se em Abelardo II na última cena, sob os acordes da marcha nupcial e perante o cadáver do ex-noivo. A peça expõe sem rodeios a condição de objeto sexual ostentada pela personagem. Também ela muda de mãos, permanecendo todavia vinculada ao segmento social capaz de suprir suas demandas materiais. "Oh! Good business!" afirma Mr. Jones encerrando o espetáculo.

Ao escrever O rei da vela, Oswald de Andrade coloca a dramaturgia brasileira em pé de igualdade com o experimentalismo mais avançado em termos internacionais. Malgrado os momentos em que resvala para um discurso panfletário típico da pedagogia comunista de então (incluindo enunciados ideológicos inteiramente desnecessários e que podem mesmo ser destacados do texto sem prejuízo de sua unidade), temos que reconhecer a modernidade de seu esquema construtivo, que guarda inúmeras semelhanças com o teatro europeu de vanguarda do início do século e com os trabalhos de Piscator, Brecht e Meyerhold. Hoje, pode-se afirmar que seu experimentalismo não encontra paralelo no teatro brasileiro dos anos 30. Desta forma, ao aproximar a concepção teatral vanguardista a uma visão dialética do processo histórico brasileiro, num de seus momentos mais cruciais, Oswald de Andrade constrói um texto comprometido com a ruptura, tanto na expressão quanto no pensamento.

"2ANDRADE. O rei da vela, p. 106-7.

${ }^{13}$ IBIDEM. p.111-2.

${ }^{14}$ IBIDEM. p.114. 
A B STRACT

The following text attempts to establish a relationship between the modernism of Oswald de Andrade's $\mathrm{O}$ rei $d a$ vela and the authour's political project, as well as to point out some confluences with Brecht, Piscator and Meyerhold.

\author{
KEY WORDS \\ anthropofagy, vanguard, engagement, Marxism
}

\title{
REFERÊNCIAS BIBLIOGRÁFICAS
}

Andrade, Oswald de. Manifesto Antropófago. In: Andrade, Oswald de. Do Pau-Brasil à Antropofagia e às utopias. 2 ed. Rio de Janeiro: Civilização Brasileira, 1978.

Andrade, Oswald de. Manifesto da Poesia Pau-brasil. In: Andrade, Oswald de. Do Pau-Brasil à Antropofagia e às utopias. 2 ed. Rio de Janeiro: Civilizaçāo Brasileira, 1978.

Andrade, Oswald de. O rei da vela.

Andrade, Oswald de. Serafim Ponte Grande. São Paulo: Global, 1984.

Brecht, Bertolt. Pequeno organon para o teatro. In: BreCht, Bertolt. Estudos sobre teatro.

Trad. Fiama Paes Brandão. Rio de Janeiro: Nova Fronteira, 1978.

HelenA, Lúcia. Tótens e tabus da modernidade brasileira. Rio de Janeiro: Tempo Brasileiro/ UFF, 1985.

Teatro moderno. São Paulo: Perspectiva, 1977. 